\title{
A Study on Inequality of women in Education using Fuzzy Approach
}

\author{
A. Victor Devadoss, PhD \\ Associate Professor, \\ Department of Mathematics, \\ Loyola College, Chennai -34,India
}

\author{
M. Rekha \\ Research Scholar, \\ Department of Mathematics, \\ Loyola College, Chennai - 34,India
}

\begin{abstract}
Education plays a major role for the development of human beings to recognize their rights in terms of social, political and economic growth of the country. More than one-third of women around the world who are illiterate are Indian women. Still women are excluded from education due to practices of inequalities in the society. Thus, the inequalities of women in education not only affects the women's lives but also on the economic developments of the country. The aim of the paper is to identify the factors which creates hurdles for women in getting education by using Fuzzy logic as it helps to study the uncertainties. Here Section one deals with Introduction. Section two gives definitions. In section three description of the problem is explained. Section four deals with the adaptation of the problem. Ultimately section five reveals the conclusion.
\end{abstract}

\section{Keywords}

Fuzzy Cognitive Bimaps, Factors, Inequalities, Education, economic growth.

\section{INTRODUCTION}

Fuzzy set theory was introduced by L.A.Zadeh [1] in 1965 to deal with vagueness and imprecise. In 1976. Axelrod [2] used cognitive maps to study decision making in social and political system. Later using the concepts of neural networks and fuzzy logic Bart Kosko proposed Fuzzy Cognitive Maps (FCM) in 1986[3]. FCMs is a collection of classes and represent causal relations between classes. It works on the opinions of experts. By using Fuzzy Cognitive Map many researchers have developed the models namely Combined overlap Fuzzy Cognitive Map[4], Combined Disjoint Fuzzy Cognitive Map[4],Combined Fuzzy Cognitive Map[5],Triangular Fuzzy Cognitive Map[6] Delphi Adapted Fuzzy Cognitive Map[7]. Fuzzy Cognitive Bimaps was pioneered by W.B.Vasantha Kandasamy et all in 2005 in the book entitled "Application of bimatrices to some fuzzy and Neutrosophic models"[8]. Fuzzy Cognitive Bimaps was used when two sets of attributes are to be analyzed which may be disjoint or unrelated or overlapping set and works on an unsupervised data. It saves time, simultaneously two experts opinion are compared at each step and ultimately gives bihidden pattern for the problem. In this paper the factors given by two experts are overlapping, So Fuzzy cognitive Bimaps was chosen to study the inequalities faced by women in education.

\section{DEFINITIONS}

Definition 2.1: When the two nodes of the Fuzzy Cognitive Bimaps are fuzzy sets then it is called fuzzy binodes.

Definition 2.2: FCBMs with edges weight or causalities from the set $\{-1,0,1\}$ are called simple FCBMs.
Definition 2.3: A Fuzzy Cognitive Bimaps (FCBMs) are fuzzy signed directed bigraphs with concepts like policies, events etc, as binodes and causalities as edges. It represents causal relationship between the Concepts.

Definition 2.4: Consider the binodes $\mathrm{C}_{1}, \mathrm{C}_{2}, \ldots, \mathrm{C}_{\mathrm{n}}$, $C_{1}^{\prime}, C_{2}^{\prime}, \ldots, C_{n}^{\prime}$ of the FCBM. Suppose the directed graph is drawn using edge weight $e_{i j} \in\{-1,0,1\}$. The matrix $M$ be defined by $\mathrm{M}=e_{i j}^{p}$ where $e_{i j}^{p}$ is the weight of the directed edge $C_{i} C_{j} . M$ is called the adjacency matrix of Fuzzy cognitive bimaps, also known as the connection bimatrix of the FCBM. It is important to note that all bimatrices associated with an FCBMs are always square matrices with diagonal entries as zero.

Definition 2.5:Let $\left\{\mathrm{C}_{1}, \mathrm{C}_{2}, \ldots, \mathrm{C}_{\mathrm{n}},\right\},\left\{C_{1}^{\prime}, C_{2}^{\prime}, \ldots, C_{n}^{\prime}\right\}$ be the two nodes of a FCBM. A is called instantaneous state bivector and it denotes the on-off position of the node at an instant.

$$
\begin{gathered}
a_{j}^{1}= \begin{cases}1 & \text { if } j \text { jth state is in ON } \\
0 & \text { if } j \text { jth state is in OFF }\end{cases} \\
a_{j}^{2}=\left\{\begin{array}{l}
1 \text { if } j \text { jth state is in ON } \\
0 \text { if } j \text { jth state is in OFF }
\end{array}\right.
\end{gathered}
$$

For $\forall \mathrm{j}=1 \ldots \ldots \mathrm{n}$

Definition 2.6:Let $\left\{\mathrm{C}_{1}, \mathrm{C}_{2}, \ldots, \mathrm{C}_{\mathrm{n}}, C_{1}^{\prime}, C_{2}^{\prime}, \ldots, C_{n}^{\prime}\right\}$ be the two nodes of a FCBM. Let $\overline{C_{1} C_{2}}, \overline{C_{2} C_{3}}, \ldots, \overline{C_{i} C_{j}}$, $\overline{C_{1}^{\prime} C_{2}^{\prime}}, \overline{C_{2}^{\prime} C_{3}^{\prime}}, \ldots, \overline{C_{i}^{\prime} C_{j}^{\prime}}$ be the two edges of the FCBM (i $\left.>\mathrm{j}\right)$ then the edges form a directed Bicycle. An FCBM is said to be cyclic if it possesses a directed cycle otherwise it is called acyclic.

Definition 2.7: An FCBM is said to be cyclic if it has feedback

Definition 2.8:Where there is a feedback an FCBM,i.e, when the causal relations flow through a cycle in a revolutionary way, the FCBM is called a dynamical system.

Definition 2.9: Let $\overline{C_{1} C_{2}}, \overline{C_{2} C_{3}}, \ldots, \overline{C_{i} C_{j}}, \quad \overline{C_{1}^{\prime} C_{2}^{\prime}}, \overline{C_{2}^{\prime} C_{3}^{\prime}}, \ldots, \overline{C_{i}^{\prime} C_{j}^{\prime}}$ be a cycle. suppose $\mathrm{C}_{\mathrm{m}}$ is switched $\mathrm{ON}$ and if the causality flows through the edges of a cycle and if it again comes to $C_{m}$, then we say that the dynamical system repeats. This true for any node $C_{m}$ for $\{m=1,2,3 \ldots, n\}$. The equilibrium state for this dynamical system is called the bihidden patterns. 
Definition 2.10:If the equilibrium state of a dynamical system is a unique state bivector, then it is called a fixed bipoint.

Definition 2.11: If the state bivector repeats in the form of $A_{1}^{t} \rightarrow A_{2}^{t} \rightarrow \ldots \ldots A_{i}^{t} \rightarrow A_{1}^{t}$ where $\mathrm{t}=1,2$ then this equilibrium is called limit bicycle

\section{DESCRIPTION OF THE PROBLEM}

Education is an instrument for the development of human beings to recognize their rights in terms of social, political and economic growth of the country. Inequality in education is a major infringement of the rights of women and girls.Due to domestic responsibility mostly eldest female child in the family use to discontinue from the school [10]. According to census 2011 in India - literacy rate of Male is 82.14 per cent and female literacy rate is 65.46 per cent[11]. According to United Nations Educational, Scientific and Cultural organisation (UNESCO) released the eAtlas of gender inequality in education (2016) reveals that Almost 16 million girls between the ages 6 and 11 will never get chance to read or write, 1 out of 8 children between the ages 6 and 15 are denied to basic education and the girls are the first to be excluded, Globally $10 \%$ of all girls between the ages of 6 and 11 are denied to right to education compared to 8 per cent of all boys and 757 million adults and 115 million of youths cannot read or write. Two -Thirds of them are women[12]. An women faces imperils and difficulties due to social environment because women always lived as subordinate to men. Though women education plays a very important role in the overall development of the country and also improve the quality of life but still they are excluded from education due to practices of inequalities in the society.

\section{ADAPTATION OF THE PROBLEM}

Let us consider the two set of attributes say $F_{1}, \ldots . . F_{n}$, $\mathrm{S}_{1}, \mathrm{~S}_{2}, \ldots, \mathrm{S}_{\mathrm{p}}$ where $\mathrm{n}, \mathrm{p}$ are finite and that are associated with the causes of inequality of women in education. B is the connection bimatrix. then passing the state vector $\mathrm{X}$ into Connection Matrix B. By thresholding process the resultant vector are converted into signal function and taking the highest values to be in ON state and other values in OFF state as 1 and 0 . It yields a new vector $\mathrm{Y}$. The process has been repeated until limit bicycle is obtained.

Attributes given by first expert

$F_{1}$ - Poverty

$\mathrm{F}_{2}$ - Domestic Works

$\mathrm{F}_{3}$ - Socio cultural preferences

$\mathrm{F}_{4^{-}}$Child marriage

$\mathrm{F}_{5}$ - Parental education

$\mathrm{F}_{6}$ - Family Conflicts

Attributes given by second expert

$\mathrm{S}_{1}$-Poverty

$S_{2}$ - Insecurity for girls in the society

$\mathrm{S}_{3}$ - Male Dominance

$\mathrm{S}_{4}$ - Father a drunkard/mother dead

$\mathrm{S}_{5}$ - having three or four female children in the family

$\mathrm{S}_{6}$ - Low motivation by parents
Now the related directed bigraph is given below

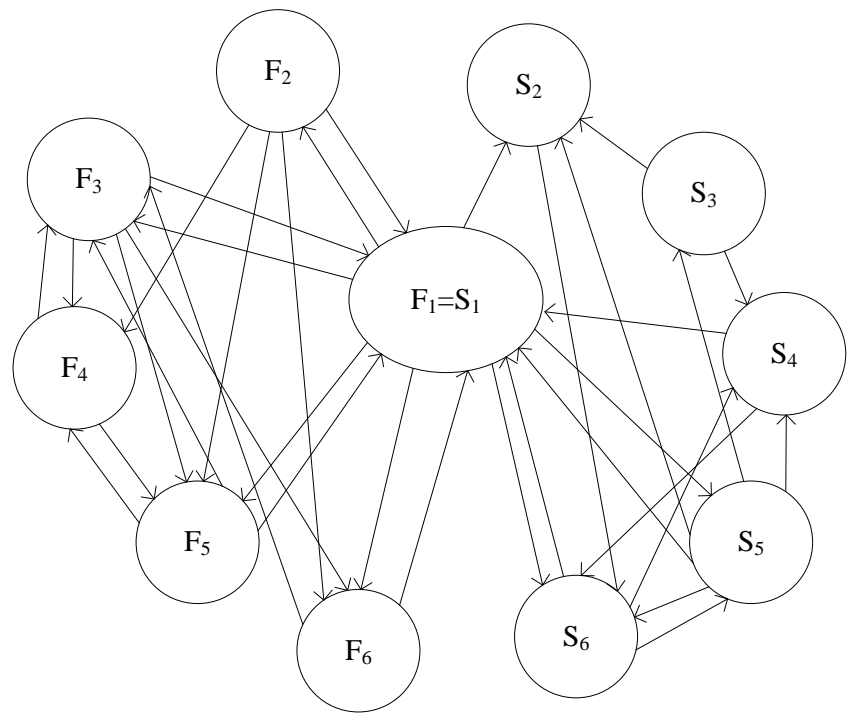

Fig 1 Directed bigraph

With the help of expert's opinion the connection bimatrix is given as $\mathrm{B}$

$$
\begin{aligned}
& B=B_{1} \cup B_{2} \\
& =\left[\begin{array}{llllll}
0 & 1 & 1 & 0 & 1 & 1 \\
1 & 0 & 0 & 1 & 1 & 1 \\
1 & 0 & 0 & 1 & 1 & 1 \\
0 & 0 & 1 & 0 & 1 & 0 \\
1 & 0 & 1 & 1 & 0 & 0 \\
1 & 0 & 1 & 0 & 0 & 0
\end{array}\right] \cup\left[\begin{array}{llllll}
0 & 1 & 0 & 0 & 1 & 1 \\
0 & 0 & 0 & 0 & 0 & 1 \\
0 & 1 & 0 & 1 & 0 & 0 \\
1 & 0 & 0 & 0 & 0 & 1 \\
1 & 1 & 1 & 1 & 0 & 1 \\
1 & 0 & 0 & 1 & 1 & 0
\end{array}\right]
\end{aligned}
$$

Let us consider an Attribute $\mathrm{X}$ is in $\mathrm{ON}$ state and other binodes are in OFF state

$$
\begin{aligned}
X & =\left(\begin{array}{llllll}
1 & 0 & 0 & 0 & 0 & 0
\end{array}\right) \cup\left(\begin{array}{llllll}
1 & 0 & 0 & 0 & 0 & 0
\end{array}\right) \\
& =\left(\begin{array}{llll}
X_{1} & \cup & X_{2}
\end{array}\right)
\end{aligned}
$$

The Impact of $\mathrm{X}$ on the dynamical system $\mathrm{B}$ is given by

$$
\begin{aligned}
& \mathrm{X}=\left(\mathrm{X}_{1} \cup \mathrm{X}_{2}\right)\left(\mathrm{B}_{1} \cup \mathrm{B}_{2}\right) \\
& =\left(\mathrm{X}_{1} \mathrm{~B}_{1}\right) \cup\left(\mathrm{X}_{2} \mathrm{~A}_{2}\right)
\end{aligned}
$$

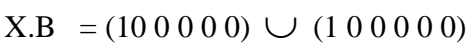

$$
\begin{aligned}
& =\left(\begin{array}{llllll}
0 & 1 & 1 & 0 & 1 & 1
\end{array}\right) \cup\left(\begin{array}{llllll}
0 & 0 & 0 & 0 & 1 & 1
\end{array}\right) \\
& \hookrightarrow\left(\begin{array}{llllll}
1 & 1 & 1 & 0 & 1 & 1
\end{array}\right) \cup\left(\begin{array}{llllll}
1 & 1 & 0 & 0 & 1 & 1
\end{array}\right) \\
& =\mathrm{X}_{1}^{\prime} \cup \mathrm{X}_{2}^{\prime} \\
& \mathrm{X}^{\prime} \cdot \mathrm{B}=\mathrm{X}_{1}^{\prime} \cup \mathrm{X}_{2}^{\prime} \cdot \mathrm{B} \\
& =X^{\prime} 1 A_{1} \cup X^{\prime} 2 A_{2} \\
& =\left(\begin{array}{llllll}
4 & 1 & 3 & 3 & 3 & 3
\end{array}\right) \cup\left(\begin{array}{llllll}
2 & 2 & 1 & 2 & 2 & 3
\end{array}\right) \\
& \hookrightarrow\left(\begin{array}{lllll}
1 & 1 & 1 & 1 & 11
\end{array}\right) \cup\left(\begin{array}{lllll}
1 & 1 & 1 & 1 & 11
\end{array}\right) \\
& =\mathrm{Y} \\
& \mathrm{Y} . \mathrm{B}=\left(\mathrm{Y}_{1} \cup \mathrm{Y}_{2}\right)\left(\mathrm{B}_{1} \cup \mathrm{B}_{2}\right) \\
& =\left(\mathrm{Y}_{1} \mathrm{~B}_{1}\right) \cup\left(\mathrm{Y}_{2} \mathrm{~B}_{2}\right)
\end{aligned}
$$


$=\left(\begin{array}{llllll}4 & 1 & 4 & 3 & 4 & 3\end{array}\right) \cup\left(\begin{array}{llllll}3 & 3 & 1 & 3 & 2 & 4\end{array}\right)$

$\hookrightarrow\left(\begin{array}{llllll}1 & 1 & 1 & 1 & 11\end{array}\right) \cup\left(\begin{array}{lllll}1 & 1 & 1 & 1 & 11\end{array}\right)$

$=\mathrm{A}$

Hence the limit bipoint is $\left(\begin{array}{llllll}1 & 1 & 1 & 1 & 1 & 1\end{array}\right) \cup\left(\begin{array}{llllll}1 & 1 & 1 & 1 & 1 & 1\end{array}\right)$. According to the opinion of first and second experts when poverty is kept in ON state all the attributes such as Domestic Works ,Socio cultural ,Child marriage ,Parental education . Family Conflicts, Insecurity for girls in the society, Male Dominance, Father a drunkard/mother dead, having three or four female children in the family and Low motivation by parents are the problems faced by women in getting education.

The set of limit points corresponding to different Input Bivectors is given below

Table 1. Limit points for Different Input Bivectors

\begin{tabular}{|c|c|}
\hline Input bivectors & Limit bicycle \\
\hline$(100000),(100000)$ & $(111111) \cup(111111)$ \\
\hline$(010000),(010000)$ & $(111111) \cup(111111)$ \\
\hline$(001000),(001000)$ & $(111111) \cup(111111)$ \\
\hline$(000100),(000100)$ & $(111111) \cup(111111)$ \\
\hline$(000010),(000010)$ & $(111111) \cup(111111)$ \\
\hline$(000001),(000001)$ & $(111111) \cup(111111)$ \\
\hline
\end{tabular}

\section{CONCLUSION}

By using Fuzzy cognitive Bimaps it is observed that the attributes given by first experts namely Poverty, domestic works, socio cultural, Child marriage , Parental education, family conflicts are all in ON state. Similarly the attributes of second experts includes low motivation by parents, Insecurity of girls in the society, Male dominance, Father Drunkard, Having three or more female children in the family, lack of economic support are all in on state. All these factors are responsible for the inequality of women in education. In order to bring gender equality it is essential to focus on the education by providing equal opportunities to men and women in every walk of life.

\section{FUTURE DIRECTION}

Education is one of the tool integrated for the empowerment of the women in the society. These are the following categories can be focused on the future study

1) Psychological effects faced by girls in the society

2) Relation between gender inequality in education and economic growth of the country can be studied

3) Further research can be concentrated on the problem faced by girls in terms of rural and urban areas separately.
4) Though Government has introduced various policies and programs to improve the female literacy. A study can done how the policies and programs are useful to them.

\section{ACKNOWLEDGMENTS}

This research work is supported by UGC Scheme RGNF Award letter NoF1-17.1/2016-17/RGNF-2015-17-SC-TAM18451/(SA-IIIWebsite)

\section{REFERENCES}

[1] Zadeh L.A (1965), Fuzzy sets, Information Control, 8, 338-353..

[2] R.Axelrod, Structures of decision: The Cognitive Map of Political elites, Princeton, N.J: Princeton University Press, 1976

[3] Kosko.B, Fuzzy Cognitive Map, International Journal of Man Machine Studies, 34(1986), 65-75.

[4] W.B.Vasantha Kandasamy, A.Victor Devadoss, Some New Fuzzy Techniques",Jour of Inst of Mat \& Comp,sci.(Math ser), Vol 17, No (2004), 157-160.

[5] Kosko, Hidden Patterns in combined and adaptive knowledge networks, international Conference of neural networks(ICCN-86),(1988)

[6] M.Clement Joe Anand, A.Victor Devadoss, Using New Triangular Fuzzy Cognitive Maps(TrFCM) to analyze the cause of Divorcee in family, International Journal of Communications Networking System,Vol 02,Dec 2013.

[7] A.Praveen Prakash, N.Vanathi,Delphi Triangular Fuzzy Cognitive Map(DTCM), International Journal of Applied Engineering Research, ISSN: 0973-4562, Vol 10,No (2015).

[8] Vasantha Kandasamy and Smarandache,K.Illanthenral, "Application of Bimatrices to some Fuzzy and Neutrosophic models, Hexis, Phoenix, USA 2005

[9] Dr.Jitendra kumar et all, status of women education in India, Education confab volz no 4, April 2013,ISSN: 2320-009

[10] UNICEF (2014), A Situational study of India, Global Initiative on out-of school children, New Delhi.

[11] Literacy Rate of India 2011 http://indiafacts.in/indiacensus-2011/literacy-rate-india-2011/

[12] UNESCO released eAtlas of Gender Inequality in Education [online] http://www.jagranjosh.com/currentaffairs/unesco-released-eatlas-of-gender-inequality-ineducation-1458207317-1. 